\title{
Low Carbon Environmental Benefit Analysis on Electricity Production
}

\section{Based on Comprehensive Environmental Cost}

\author{
LIU Jiangyan ${ }^{1, a}$,YING Yuhang ${ }^{1, b}$ \\ ${ }^{1}$ School of Economics and Management, North China Electric Power University, Beijing, China \\ aliujiangyan6474@163.com, boliviayyh@126.com
}

\begin{abstract}
Keywords:Pollutant emission factor, Cost equivalent, Environmental cost, Low carbon environmental benefit
\end{abstract}

Abstract. Research on environmental cost calculation method for electricity production and benefit assessment method considering low-carbon energy saving, can promote the realization of low-carbon production in power industry. First, the measurement for environmental factors and costs were studied in the paper, and then the way to realize low carbon benefit calculation based on comprehensive environmental cost was introduced. Finally, the calculation results of low carbon environmental benefit in a certain area were obtained, and the effect of low carbon production on generation plan, network loss and user side were verified.

\section{Introduction}

The main production characteristics of power industry is dominated by coal, the production process will adversely affect the external environment. Accordingly, with the development of electric power production, the environmental control cost for the restoration of external environment will continue to be increased. The measurement for environmental factors and costs were studied in the paper first, and then the way to calculate environmental cost of each pollutant through environmental factors and cost equivalents was introduced, and the low carbon environmental benefit calculation model based on comprehensive environmental cost was put forward. Finally, the effect of low carbon production on generation plan, network loss and user side were verified through an example.

\section{The Calculation of Environmental Factors}

According to calculation methods and ideas in guideline, the calculation models for each environmental factor can be established by using the power generation, resource consumption, fuel type, pollutant emissions and other indicators of each unit in power system.

(1) Average carbon dioxide emission factor

$$
f_{\mathrm{CO}_{2}}=\frac{M_{\mathrm{CO}_{2}}}{Q}=\frac{F C_{i} \times N V C_{i} \times h_{\mathrm{CO}_{2}, i}}{Q}
$$

In the formula, $M_{\mathrm{CO}_{2}}$ is the total amount of $\mathrm{CO}_{2}$ emissions; $Q$ is the total amount of unit on grid electricity; $F C_{i}$ is the unit consumption of fuel $\mathrm{i} ; N V C_{i}$ is the net calorific value of fuel $\mathrm{i}$ (energy content, GJ / mass or volume unit); $h_{\mathrm{CO}_{2}, i}$ is the $\mathrm{CO}_{2}$ emission factor of fuel $\mathrm{i} ; \mathrm{i}$ is the kind of fossil fuels that consumed by unit.

(2) Average sulfur dioxide emission factor

$$
f_{\mathrm{SO}_{2}}=M_{\mathrm{SO}_{2}} / Q
$$

In the formula, $M_{\mathrm{SO}_{2}}$ is the total amount of $\mathrm{SO}_{2}$ emissions, and it can be calculated by monitoring; 
$Q$ is the total amount of unit on grid electricity.

(3)Average nitrogen oxide emission factor

$$
f_{N O_{X}}=M_{N O_{X}} / Q
$$

In the formula, $M_{N O_{X}}$ is the total amount of $\mathrm{NO}_{\mathrm{X}}$ emissions, and it can be calculated by monitoring; $Q$ is the total amount of unit on grid electricity.

(4) Average PM emission factor

$$
f_{P M}=M_{P M} / Q
$$

In the formula, $M_{P M}$ is the total amount of PM emissions, and it can be calculated by monitoring; $Q$ is the total amount of unit on grid electricity.

\section{The Calculation of Environmental Cost}

\section{The Origin of Environmental Cost}

After the introduction of carbon trading mechanism, the total cost of electricity production is the sum of production cost and the environmental cost, as shown in Fig. 1.

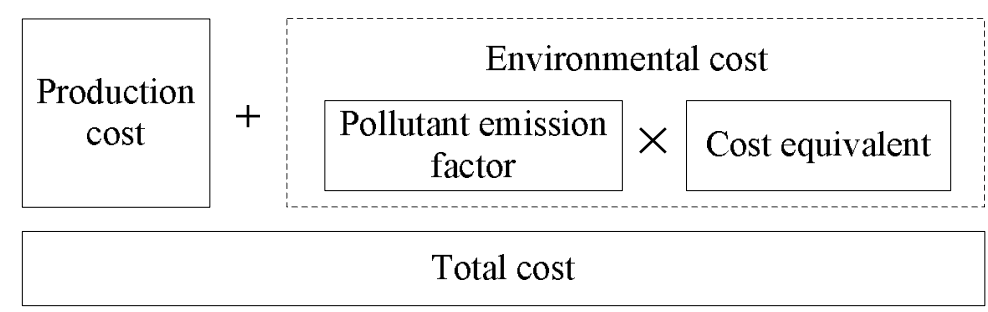

Figure 1 The Structure of Total Cost

In this paper, the environmental cost is divided into two categories, one is the resource consumption cost, and the other is the pollution control cost. The resource consumption class mainly refers to coal consumption, and in this paper, coal consumption and water consumption cost are calculated in production cost. Environmental cost mentioned in this paper refers to the cost that beside above production cost, when the power plant use this part of resource, other companies can not use it any more and they will generate the opportunity cost, so the power plant need to pay additional fees for such resources consumption.

Pollution control class refers to the pollutants that have impact on environment, mainly including $\mathrm{CO}_{2}, \mathrm{SO}_{2}, \mathrm{NO}_{\mathrm{x}}$ and solid particles. So a series of measures need to be taken in order to limit emissions within a line, but these measures need to spend some costs and these costs constitute a comprehensive environmental cost.

The Estimation of Cost Equivalent

Pollutant cost equivalent is the cost of per unit pollutant emission. With the adjustment of pollution tax and the construction of national carbon trading market, the pollution tax and carbon price will be more in line with the actual cost of pollution control.

(1) The estimation of $\mathrm{CO}_{2}$ cost equivalent

Because $\mathrm{CO}_{2}$ is the most important factor for global warming, other country's carbon tax as the standard, the current carbon tax policy in China is not implemented, carbon price in China's carbon market can be used as the standard for $\mathrm{CO}_{2}$ cost equivalent.

(2) The estimation of other pollutants cost equivalent

For sulfur dioxide, nitrogen oxides, calculating based on "Management on PollutantDischarge 
Fee Standard" and determining the sulfur dioxide pollution fee is 1.2 yuan $/ \mathrm{kg}$, nitrogen oxide is also 1.2 yuan $/ \mathrm{kg}$. The specific cost equivalentsof sewage and solid particulatehave no relevant policies.

\section{The Calculation of Environmental Costs}

By measuring the environmental factors and cost equivalents of pollutants, the management cost of the unit pollutants can be obtained. The average pollutant emission factor multiplied by the pollution control cost equivalent, can get the comprehensive environmental cost that should be paid by unit electricity.

$$
\begin{aligned}
C_{\mathrm{Com}} & =f_{p} \times e_{p} \\
& =f_{\mathrm{CO}_{2}} \times e_{\mathrm{CO}_{2}}+f_{\mathrm{SO}_{2}} \times e_{\mathrm{SO}_{2}}+f_{\mathrm{NO}_{2}} \times e_{\mathrm{NO}_{2}}+f_{\mathrm{PM}} \times e_{\mathrm{PM}}
\end{aligned}
$$

\section{Low carbon environmental protection comprehensive benefit assessment model}

\section{Low carbon environmental protection comprehensive benefit assessment model}

The low carbon and environmental protection comprehensive benefit in electric power production is the sum of the benefit of primary energy conservation and the benefit from the reduction of all kinds of pollutant emissions by power plants.

$$
E_{\mathrm{Com}}=E_{\mathrm{CO}_{2}}+E_{\mathrm{SO}_{2}}+E_{\mathrm{NO}_{x}}+E_{\mathrm{PM}}(6)
$$

In the formula, $E_{c o m}$ is the low carbon comprehensive benefit of electricity production; $E_{\mathrm{CO}_{2}}, E_{\mathrm{SO}_{2}}, E_{\mathrm{NO}_{\mathrm{x}}}, E_{\mathrm{PM}}$ is the emission reduction benefit of carbon dioxide, sulfur dioxide, nitrogen oxides and solid particles respectively.

The external cost that had been saved (ie, comprehensive environmental cost) during the lowcarbon electricity production, can be understood as a lowcarbon comprehensive benefit. The low carbon environmental protection comprehensive benefit of electricity production is the negative value of environmental cost.

$$
E_{\text {Com }}=-1 * C_{\text {Com }}(7)
$$

\section{Comprehensive Benefit Evaluation Process}

By measuring raw data from each power plant, the average emission factor of carbon dioxide, sulfur dioxide, nitrogen oxide and solid particle were obtained, and the emission factor multiplied by the total generating capacity of grid can get the total emission amount of each pollutant indicator. By multiplying the separated cost equivalent and the total amount of emissions, the low carbon environmental protection comprehensive cost of each pollutant can be obtained, the total low carbon environmental protection comprehensive cost can be obtained by adding each pollutant cost mentioned above, as shown in Fig. 2. 


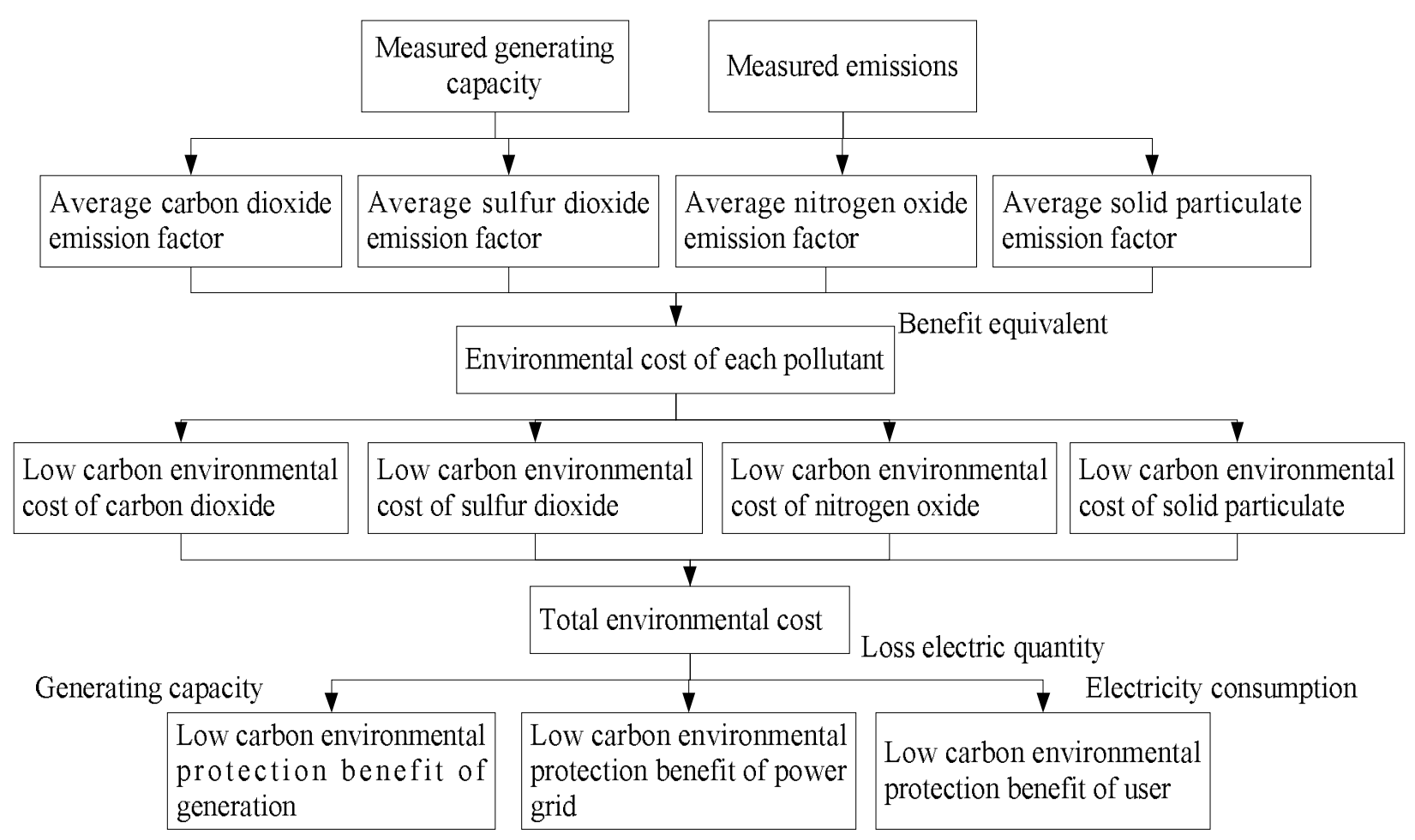

Figure 2 Comprehensive Benefit Evaluation Process

\section{Example Analysis}

Example analysis based on the actual data of one province, measured data including generating capacity of each generation unit, $\mathrm{CO}_{2}$, sulfur dioxide, nitrogen oxide emissions per ton of coal produced were collected. Take power generation standard coal consumption of $292 \mathrm{~g} / \mathrm{kWh}$. Average carbon dioxide emission factor in thermal power unit is $0.00015184 \mathrm{t} / \mathrm{kWh}$, the average sulfur dioxide emission factor is $0.000001022 \mathrm{t} / \mathrm{kWh}$, the average nitrogen oxide emission factor is $0.00000216 \mathrm{t} / \mathrm{kWh}$, the averagesolid particulate emission factor is $0.000000292 \mathrm{t} / \mathrm{kWh}$, as shown in Table 1 and Table 2.

Table 1The Calculation of Average Emission Factor

\begin{tabular}{ccccc}
\hline Power plant & $\begin{array}{c}\text { Average carbon } \\
\text { dioxide emission } \\
\text { factor[t/kWh] }\end{array}$ & $\begin{array}{c}\text { Average sulfur } \\
\text { dioxide emission } \\
\text { factor[t/kWh] }\end{array}$ & $\begin{array}{c}\text { Average nitrogen } \\
\text { oxide emission } \\
\text { factor }[\mathrm{t} / \mathrm{kWh}]\end{array}$ & $\begin{array}{c}\text { Average solid } \\
\text { particulate emission } \\
\text { factor[t/kWh] }\end{array}$ \\
\hline Thermal power plant & 0.00015184 & 0.000001022 & 0.00000216 & 0.000000292 \\
\hline
\end{tabular}

The low carbon environmental protectioncomprehensive benefit can be calculated through the benefit evaluation process. 
Table 2The Figure of Low Carbon Environmental Protection Benefit

\begin{tabular}{ccccc}
\hline & $\begin{array}{c}\text { Carbon } \\
\text { dioxide }\end{array}$ & $\begin{array}{c}\text { Sulfur } \\
\text { dioxide }\end{array}$ & $\begin{array}{c}\text { Nitrogen } \\
\text { oxide }\end{array}$ & $\begin{array}{c}\text { Solid } \\
\text { particulate }\end{array}$ \\
\hline Emission factor [t/kWh] & 0.00015184 & 0.000001022 & 0.00000216 & 0.000000292 \\
Total emissions [t] & 30031775 & 202137 & 427217 & 57753 \\
Benefit equivalent [yuan/kg] & 0.03 & 1.26 & 1.2 & 0.945 \\
$\begin{array}{c}\text { Low carbon environmental protection } \\
\text { comprehensive benefit [yuan/kWh] } \\
\text { Total low carbon environmental } \\
\text { protection comprehensive benefit } \\
\text { [yuan/kWh] }\end{array}$ & 0.0045552 & 0.00128772 & 0.00259296 & 0.00027594 \\
\hline
\end{tabular}

\section{Conclusion}

As the power production process produces pollutant emissions, the total electricity cost also includes the environmental cost. Pollutant tax and carbon price can represent the unit environmental costs of each pollutant, combined with the pollutant emissions of per unit generating capacity, environmental cost can be calculated for each pollutant. The benefit generated from low carbon electricity production process, is the comprehensive cost of various pollutants that been saved. The low carbon environmental benefit can reach 0.00871 yuan $/ \mathrm{kWh}$ through measuring. If part of the electricity in production process can achieve low carbon production, it will bring a very significant low carbon environmental benefit to power generation side, grid side and the user side.

\section{References}

[1] The Standard Management for Collecting the Fee of Discarded Sewage[J].Chinese Journal of Environmental Management,2003,(2):15-16.

[2] WANG Zhi-xuan, PAN Li, PENG Jun. Analysis of Current Status, Cost and Policies of Power Sector SO2 Emission Control[J]. Research of Environmental Sciences, 2005,18(4):11-20.

[3] KANG Chong-qing, ZHOU Tian-rui, CHEN Qi-xin. Challenges and Countermeasures for Power Generation and Transmission Companies in a Low-carbon Economy[J]. Energy Technology and Economics,2010,06:1-8.

[4] WU Xiao-wei, ZHU Fa-hua, YANG Jin-tian, ZHOU Dao-bin, YAN Li, TENG Nong, YI Yu-ping. Measurements of Emission Factors of Greenhouse Gas (CO2,N2O) from Thermal Power Plants in China[J]. Research of Environmental Sciences,2010,02:170-176.

[5] Shi Yang.Research on the Performance Evaluation of Energy-saving and Emission Reduction in Electric Power Industry[D].North China Electric Power University(Baoding),2011.

[6] SONG Xiao-hua. Energy-Conservation Route of Power Generation Industry based on LowCarbon Economy[D]. North China Electric Power University,2012.

[7] ZHAO Ting. Applied Research on the Environmental Cost of Thermal Power Enterprise[D].Zhejiang University of Technology,2013.

[8] ZHU Xiao-ming. Research on Thermal Power Enterprises Environmental Costs Accounting System and Control Methods under Low-carbon Economy [D].University of South China,2014. 